\title{
Experimental validation of a thermal model of adhesively bonded scarf repairs for CFRP composite materials incorporating cure kinetics
}

\author{
C. C. N. Bestley, S. G. R. Brown \& S. M. Alston \\ Materials Research Centre, College of Engineering, \\ Swansea University, UK
}

\begin{abstract}
Adhesively bonded scarf repairs are the preferred method of repairing modern composite structures as they provide high strength restoration and aerodynamic flushness. Curing of the adhesive bondline is carried out by locally heating the repair area. To assess repair design and heating practices simulation can be used to model both the transient heat transfer during curing and the level of cure likely to be achieved at different regions in the adhesive joint. In this paper a 3D curing model is described to simulate heat transfer through a composite component. The cure kinetics of a commercial epoxy resin adhesive have been determined using isothermal Differential Scanning Calorimetric (DSC) analysis. Using these kinetics the model is able to determine the influence of the exothermic reaction within the adhesive on the overall temperature variation within the component. An experimental programme has been carried out where composite material and bonded repair patches have been cured with thermocouples providing measured temperature/time data during the cycle. The results from the cure model are then validated by comparison with these experimental results. The cure model is capable of being used to optimise the cure cycle for a bonded repair, ensuring the maximum degree of cure of the adhesive with minimum variation of temperature within the bond line.
\end{abstract}

Keywords: cure kinetics, DSC analysis, numerical model.

\section{Introduction}

The increase in use of composites in the aerospace, automotive and civil engineering industries has led to the increasing demand for development of 
suitable repair methods [1]. Bonded repairs have been proven to restore strength without compromising structural integrity [2]. In addition, the weight reduction and aerodynamic properties of bonded repairs make them more favourable to their bolted counterpart [3].

The mechanical properties of the adhesives used for bonded repairs are highly dependent on the curing process [4,5]. Curing involves a complex set of chemical reactions to elongate and crosslink pre-polymer molecules to form a 3D molecular network. This is followed by the materials' transition from a viscous fluid to a viscoelastic solid [6].

Experimental investigation into the curing of composites produces the most accurate and reliable results, although this is often expensive and time consuming. As a result computational models are often used to simulate the curing process. These models have the advantage of speed, low cost and the ability to simulate ideal conditions.

Various studies have been conducted to simulate the curing process for thick thermosetting matrix composites. Early work by Loos and Springer [7] formed the basis for many of the cure models that followed. Their model simulated the curing process of a flat plate in an autoclave using the finite difference method. They were able to simulate residual stress development and void formation. Later work by Bogetti and Gillespie [8] involved a two dimensional cure simulation of a thick anisotropic thermosetting composite using thermal and chemical kinetics. This model also used the finite difference method and was based on the fundamental principles discussed in the Loos and Springer paper, although with an added second dimension.

Zhu et al. [9] produced a three-dimensional cure model that simulated heat transfer across a composite component, the cure process, residual stresses developed and deformation. Finally, Cheung et al. [10] produced a threedimensional thermo-chemical cure simulation based on the Galerkin finite element method. The rate and degree of cure throughout the curing process were determined and induced residual stresses and the resulting deformation were evaluated. This paper was the most influential in the formation of the cure model used in this investigation.

\section{Model description}

A flat plate with dimensions of $560 \mathrm{~mm} \times 560 \mathrm{~mm}$ with a uniform thickness of $10 \mathrm{~mm}$ with a simple $120^{\circ} \mathrm{C}$ cure cycle was simulated. The repair area consisted of a patch of $260 \mathrm{~mm}$ diameter with $5 \mathrm{~mm}$ thickness and a $3^{\circ}$ scarf angle.

The patch is bonded into the repair area using the same commercial film adhesive as used in the DSC experiments. The cure cycle for this film adhesive is provided by the manufacturer.

The equations were solved using a Gauss-Seidel algorithm where the temperature and degree of cure were determined at each time step.

The cure kinetics equations in this work were based on the Cheung et al. [10] paper and the heat transfer methodology is based on the work of Patankar [11] entitled 'Numerical heat transfer and fluid flow'. 
The three-dimensional time dependent energy balance equation is given as:

$$
\rho C \frac{\partial T}{\partial t}=\frac{\partial}{\partial x}\left(k \frac{\partial T}{\partial x}\right)+\frac{\partial}{\partial y}\left(k \frac{\partial T}{\partial y}\right)+\frac{\partial}{\partial z}\left(k \frac{\partial T}{\partial z}\right)+S
$$

where $\rho$ is the density $\left(\mathrm{kg} \mathrm{m}^{-3}\right), \mathrm{C}$ is the specific heat capacity $\left(\mathrm{J} \mathrm{kg}^{-1} \mathrm{~K}^{-1}\right), \mathrm{k}$ is the thermal conductivity $\left(\mathrm{W} \mathrm{m}^{-1} \mathrm{~K}^{-1}\right)$ and $\mathrm{T}$ is the temperature $(\mathrm{K})$. $\mathrm{S}$ is a source term.

Discretisation of the time dependent energy balance equation forms the following equation:

$$
a_{P} T_{P}=a_{E} T_{E}+a_{W} T_{W}+a_{N} T_{N}+a_{S} T_{S}+a_{T} T_{T}+a_{B} T_{B}+b
$$

where:

$$
\begin{aligned}
& a_{E}=\frac{k_{e} \Delta y \Delta z}{(\delta x)_{e}} \quad a_{W}=\frac{k_{w} \Delta y \Delta z}{(\delta x)_{w}} \quad a_{N}=\frac{k_{n} \Delta z \Delta x}{(\delta y)_{n}} \quad a_{S}=\frac{k_{S} \Delta z \Delta x}{(\delta y)_{s}} \\
& a_{T}=\frac{k_{t} \Delta x \Delta y}{(\delta z)_{t}} \quad a_{B}=\frac{k_{b} \Delta x \Delta y}{(\delta z)_{b}} \quad \text { and } b=a_{P}^{0} T_{P}^{0}+S_{C} \Delta x \Delta y \Delta z
\end{aligned}
$$

The values of $a_{E}$ to $a_{B}$ represent the heat conductance between the grid point $P$ and the corresponding neighbour in the model where $\Delta \mathrm{x}, \Delta \mathrm{y}$ and $\Delta \mathrm{z}$ represent the dimensions of the control volume. The variable ' $b$ ' is a constant consisting of the internal energy and the rate of heat generation resulting from the term $\mathrm{S}_{\mathrm{C}}$. This term is given as:

$$
S_{C}=Q \rho / d t \quad \text { where } \mathrm{Q} \text { is the heat flow per unit mass }(\mathrm{J} / \mathrm{kg})
$$

The harmonic means of the thermal conductivities were used to account for the different materials used.

Finally the value of $T_{P}$ is defined:

$$
T_{P}=\left(a_{E} T_{E}+a_{W} T_{W}+a_{N} T_{N}+a_{S} T_{S}+a_{T} T_{T}+a_{B} T_{B}+b\right) / a_{P}
$$

This is the temperature at grid point $\mathrm{P}$.

The degree of cure, $\alpha$, is found to be related to the rate of reaction $r_{\alpha}$ by the rate equation [10]:

$$
\frac{\partial \alpha}{\partial t}=r_{\alpha} \quad \text { for } \alpha_{0}=\alpha_{i} \text { at } t=t_{i}
$$

This rate of reaction is given by the well established Kamal and Sourour [12] equation:

$$
\frac{d \alpha}{d t}=\left(K_{1}+K_{2} \alpha^{m}\right)(1-\alpha)^{n}
$$


where $\mathrm{K}$ is the rate constant of the Arrhenius equation and $\mathrm{m}$ and $\mathrm{n}$ are constants dependent on the resin system. The Arrhenius equation is used to determine the rate of chemical reactions. It represents the dependence of the rate constant $\mathrm{K}$ of chemical reactions on the absolute temperature $\mathrm{T}$ and activation energy $\mathrm{E}$ and is given as:

$$
K_{1}=A_{1} e^{\left(-E_{1} / R T\right)}
$$

where $A_{1}$ represents the pre-exponential factor $\left(\sec ^{-1}\right)$ and $E_{1}$ is defined as the activation energy $(\mathrm{J} / \mathrm{mol})$. The rate constant, $\mathrm{K}$, is the rate of reactions taking place during cure and $\mathrm{R}$ is the universal gas constant. The values for these cure kinetics and the value of $\mathrm{H}_{\mathrm{r}}$ was found using Differential Scanning Calorimetry (DSC).

\section{Cure kinetics evaluation by DSC}

Differential Scanning Calorimetry can be used to determine the glass transition temperature $\left(T_{g}\right)$ and degree of cure $(\alpha)$ of a commercial film adhesive by measuring the heat flow into and out of a sample as it is heated (at a constant heating rate) at a predefined temperature in a nitrogen purged atmosphere. This method is based on the ASTM E698-05 [13] and involves the analysis of DSC data at various heating rates to derive model-free kinetics.

Small samples (weighing approximately $20 \mathrm{mg}$ ) were placed in an aluminium pan to be used in a Perkin Elmer Jade DSC. The sample was then rapidly heated to a number of different temperatures. The exothermic reaction produced when the adhesive cured was recorded and a normalised graph was produced of each temperature.

The area under the exothermic peak was used to isolate data specific to the cure of the adhesive, and this data recorded for each temperature provided the degree and rate of cure $(\alpha, \delta \alpha / \delta$ t respectively) at each time increment.

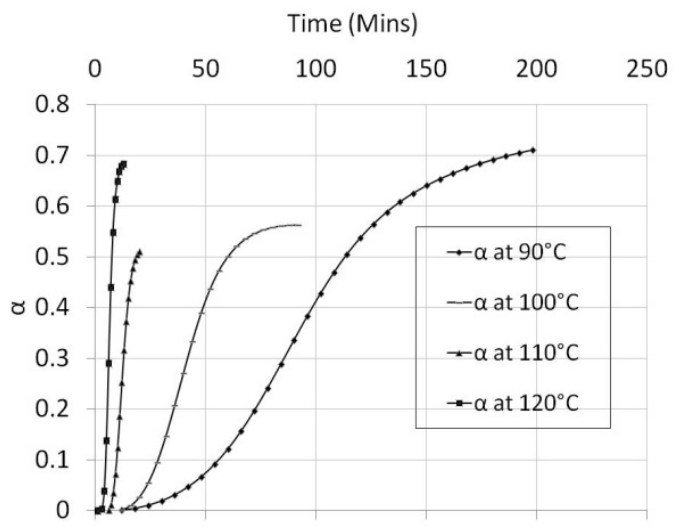

Figure 1: Degree of cure of the epoxy film adhesive. 
The equation for the rate of cure has been given as:

$$
\frac{d \propto}{d t}=\left(K_{1}+K_{2} \propto^{m}\right)(1-\propto)^{n}
$$

where $\mathrm{K}_{1}$ and $\mathrm{K}_{2}$ are rate constants and $\mathrm{m}$ and $\mathrm{n}$ are reaction orders.

Further work using the DSC measurements showed the maximum degree of cure does not reach $100 \%$ as towards the latter stages of the reaction it becomes diffusion controlled. The current model was based on a final $100 \%$ cure for the adhesive. Some models [14] have used a temperature dependent function $\alpha_{\max }$ as the maximum degree of cure to account for the diffusion controlled process in the final stages of the curing reaction. This modification of the Kamal and Sourour [12] equation is as follows:

$$
\frac{d \propto}{d t}=\left(K_{1}+K_{2} \propto^{m}\right)\left(\alpha_{\max }-\propto\right)^{n}
$$

This forms the basis for model 2 cure kinetics (see Table 1).

The least square best fit method can be used to minimise this difference between the calculated and measured values by altering the values of $\mathrm{K}_{1}, \mathrm{~K}_{2}, \mathrm{~m}$ and $\mathrm{n}$. This produces 'fitted' values of $\mathrm{K}_{1}, \mathrm{~K}_{2}, \mathrm{~m}$ and $\mathrm{n}$ for all temperatures which can be used to find the cure kinetics of each model.

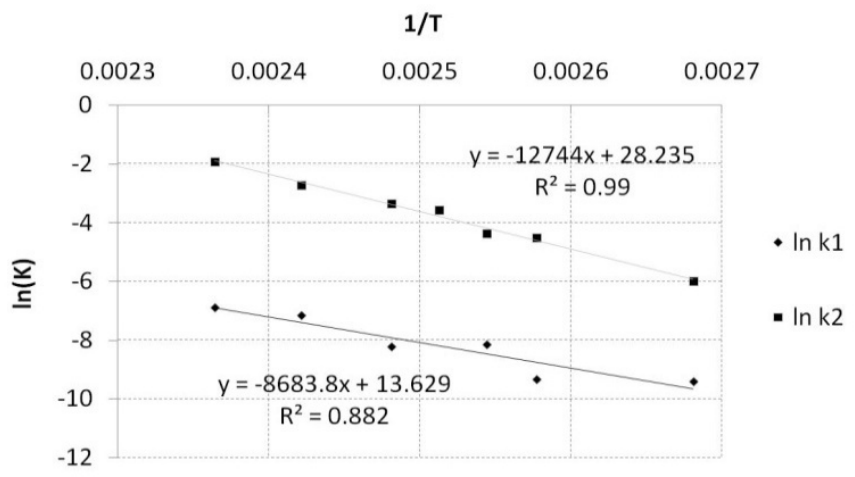

Figure 2: Model 1 Arrhenius plot of rate constants $\ln _{1}$ and $\ln K_{2}$ as a function of cure temperature.

Arrhenius found that by taking the natural logarithm (ln) of both $\mathrm{K}_{1}$ and $\mathrm{K}_{2}$ and plotting them in a graph against the inverse of temperature (1/T) two linear correlations are produced, with gradient and intercept of (-E/R) and A respectively [15]:

$$
\ln \left(K_{1}\right)=\left(-E_{1} /_{R T}\right)+\ln \left(A_{1}\right)
$$


This method was then used to find the cure kinetics for model 2. The cure kinetics for both models were found to be:

Table 1: $\quad$ Cure kinetics.

\begin{tabular}{|c|c|c|c|c|c|c|}
\hline & $\mathrm{A}_{1}\left(\mathrm{sec}^{-1}\right)$ & $\mathrm{A}_{2}\left(\mathrm{sec}^{-1}\right)$ & $\mathrm{E}_{1}(\mathrm{~J} / \mathrm{mol})$ & $\mathrm{E}_{2}(\mathrm{~J} / \mathrm{mol})$ & $\mathrm{m}$ & $\mathrm{n}$ \\
\hline 1 & $8.2985 \times 10^{5}$ & $1.8294 \times 10^{12}$ & 72203 & 105960 & 1.1655 & 3.0108 \\
\hline 2 & $3.435 \times 10^{29}$ & $4.8042 \times 10^{6}$ & 257126 & 64296 & 0.8892 & 1.5493 \\
\hline
\end{tabular}

These values were placed in the model to determine the effect of the exothermic reaction during cure on the overall heat transfer through a composite component.

\section{Cure model results}

A cell-centred finite difference model was formulated so that the component geometry, cure cycle, the temperature of the local environment and insulation could be changed with each simulation. This is so that the model can simulate the bonding of repairs on different components in various conditions. Experiments discussed later were based on some of these simulations, so that the model could be validated.

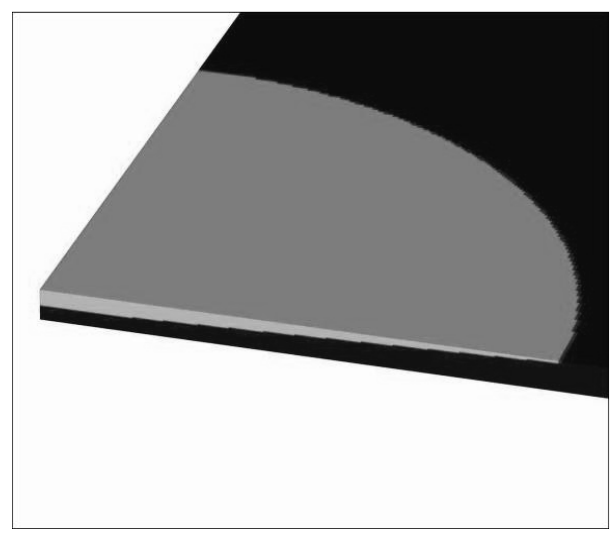

Figure 3: $\quad$ Model geometry (quarter).

The following table shows an example of the simulations used to determine the effects of component thickness, ambient temperature and ramp rate. Insulation effects were controlled by a change in heat transfer coefficient (HTC).

As expected, an increase in component thickness leads to an increase in variation in temperature through the panel, particularly at the edges. An increase in the surrounding temperature led to a more even distribution of heat through the panel. An increase in ramp rate to the desired cure temperature also provided a small improvement of heat distribution but did not significantly reduce the heat 
Table 2: $\quad$ Model variations.

\begin{tabular}{|c|c|c|c|c|c|}
\hline $\begin{array}{c}\text { Model } \\
\text { No. }\end{array}$ & $\begin{array}{c}\text { Cure } \\
\text { Temp } \\
\left({ }^{\circ} \mathrm{C}\right)\end{array}$ & $\begin{array}{c}\text { Thickness } \\
(\mathrm{mm})\end{array}$ & $\begin{array}{c}\text { Ambient } \\
\text { Temperature } \\
\left({ }^{\circ} \mathrm{C}\right)\end{array}$ & $\begin{array}{c}\text { Rate } \\
\left({ }^{\circ} \mathrm{C} / \mathrm{min}\right)\end{array}$ & $\begin{array}{c}\text { HTC } \\
\left(\mathrm{Wm}^{-2} \mathrm{~K}^{-1}\right)\end{array}$ \\
\hline 1 & 120 & 10 & 25 & 1 & 15 \\
\hline 2 & 120 & 20 & 25 & 1 & 15 \\
\hline 3 & 120 & 10 & 50 & 1 & 15 \\
\hline 4 & 120 & 10 & 25 & 3 & 15 \\
\hline
\end{tabular}

lost through the edges of the panel. However, the effect of ramp rate on the curing of the adhesive was significant. The increased ramp rate produced a far higher degree of cure of the adhesive during the early stages of the cure cycle.

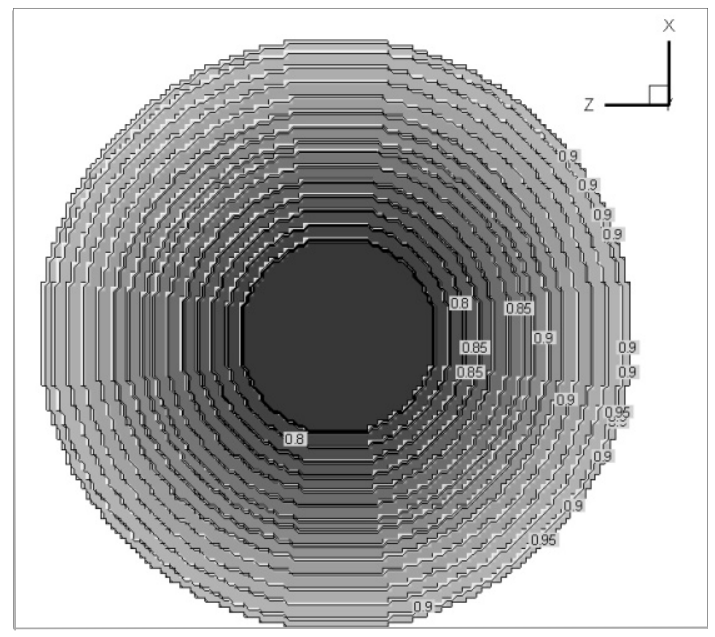

Figure 4: Degree of cure modelling.

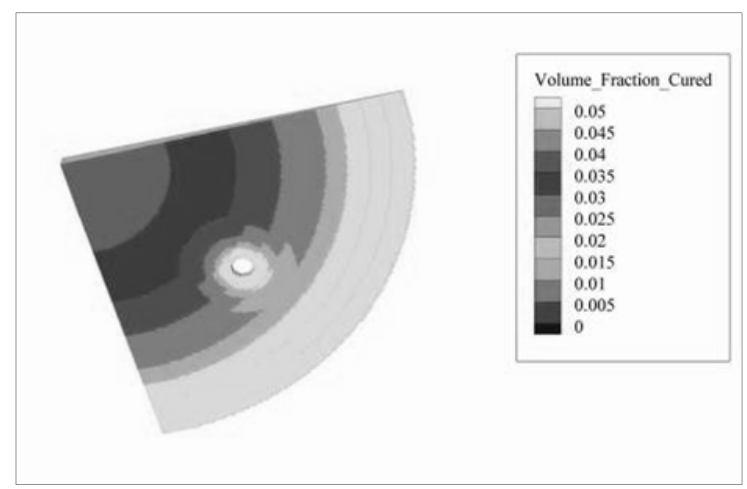

Figure 5: $\quad$ Effect of Titanium bolt on $\alpha$. 
The influence of metallic components was investigated in the form of a metallic bolt through the patch and surrounding structure. The bolt (assumed to be manufactured from titanium) has a higher thermal conductivity than the composite structure. However, the results from the simulation showed that the presence of a metallic component increased the temperature of the local area by an insignificant amount and the overall heat transfer through the component was largely unaffected.

\section{Experimentation}

The model is based on the conduction of heat from a source above the component. This is representative of a modern heating method used specifically for repair of large composite components or for in-service applications. This method involves a hot bonder used as the heat source of a number of CFRP composite components of different thickness and geometry. These results were used to validate the model and to suggest areas that required further investigation.

Thermocouples were embedded into a $900 \mathrm{~mm} \times 900 \mathrm{mmx} 10 \mathrm{~mm}$ panel in the bottom right hand corner of the panel to match the model. Thermocouples 1-16 were placed after plies 8,16,24 and 32 in the arrangement shown in figure 6 .

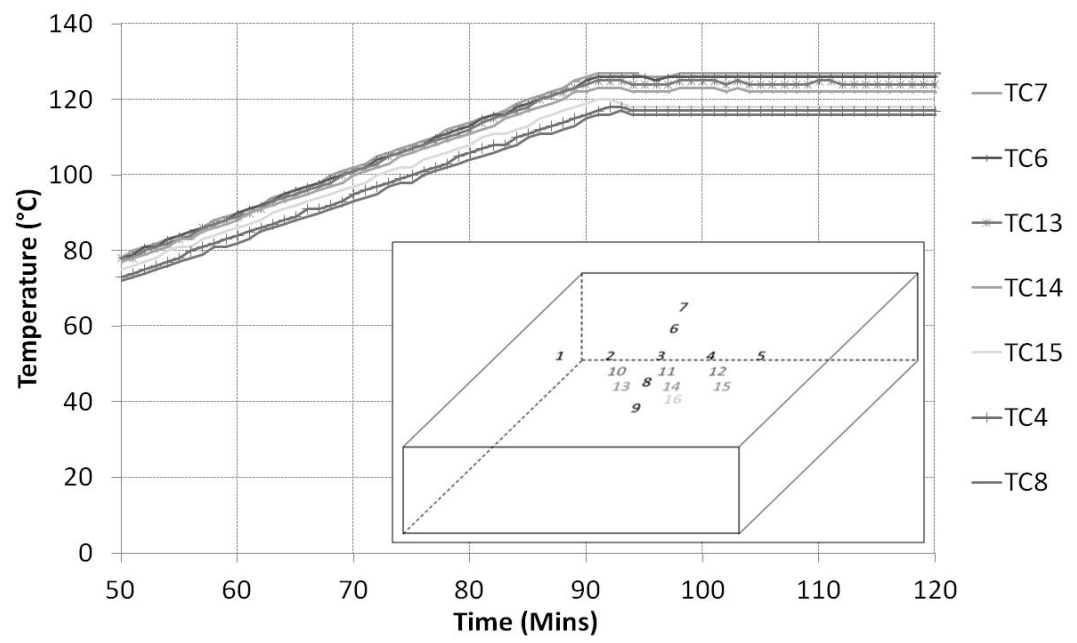

Figure 6: Embedded thermocouple readings and layout.

The centre thermocouples demonstrated little variation in temperature and were able to reach the desired cure temperature with ease. The thermocouples closer to the edges exhibited a significantly lower temperature. The results of these experiments were then compared with the cure model. 


\section{Results and discussion}

The thermocouple readings for this trial were comparable to the results produced by the cure model. The panel was inadequately insulated at the edges to clearly demonstrate heat loss through the edges and underside of the panel.

This resulted in heat lost through the edges of the panel, particularly in the corner. The model was able to demonstrate this heat loss with a high degree of accuracy.

The most significant modification was made to the heat transfer coefficient at the edges and underside of the component. From experimental data and the results from the model a small range of HTCs (between 10-20 $\mathrm{Wm}^{-2} \mathrm{~K}^{-1}$ ) were determined based on insulation and environmental temperature. This demonstrates the effectiveness of insulation and the detrimental effect environmental conditions can have on heat transfer through a composite component.

The assumptions made in the formation of the cure model should be taken into account when viewing the results.

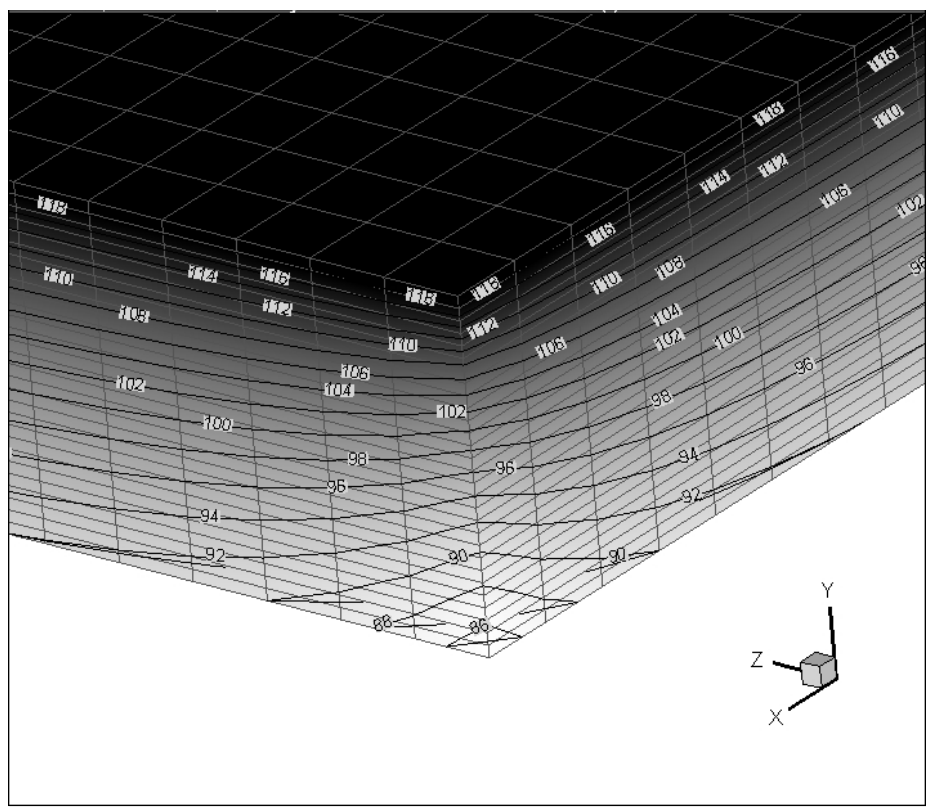

Figure 7: Corner view heat distribution.

For example, the thermal conductivity values for each material were considered to be the same in all directions. In practice, the thermal conductivity of carbon fibre in the transverse direction is approximately $25 \%$ of that in the longitudinal and through-thickness directions [16]. However, the experimental trials compare favourably with the results from the models. 


\section{Conclusions}

A finite difference model was produced to simulate heat transfer through a flat CFRP composite panel during the cure cycle of a bonded repair process. The effects of heating rates, insulation and environmental temperature were simulated and the results validated through experimental investigation.

Further modification of the model from experimental results has improved both the accuracy of the model and the ability to uniformly heat a composite component. The results from the model have provided insight into the nature of heat transfer under different conditions.

The large variance in temperature between the centre and edge thermocouples was demonstrated in both the model and experimentation.

The model provided more information as to where the heat loss is most significant, and with further trials in combination with further modelling this heat loss could be significantly reduced.

The exothermic reaction during the cure of the adhesive was determined to have an insignificant impact on the overall heat transfer through the component. The incorporation of a Titanium bolt increased the local temperature and therefore degree of cure of the adhesive in the early stages of the cure cycle. However, this became insignificant towards the latter stages of the cure.

Ongoing work will involve the optimisation of the cure cycle for bonded repair, residual stresses and deformation, and void formation.

\section{Acknowledgements}

This work was carried out as part of the CONTOUR project in collaboration with Airbus Operations Limited under Welsh Assembly Government contract reference number HE 09 COL 1030.

\section{References}

[1] Tomblin, J.S., Salah, L., Welch, J.M., Borgman, M.D., Bonded Repair of Aircraft Composite Sandwich Structures, Final Report, DOT/FAA/AR03/74, Office of Aviation Research, Washington D.C. 20591, February 2004.

[2] Baker, G., Bonded Composite Repair of Fatigue-Cracked Primary Aircraft Structure. Composite Structures, 47(1-4), pp. 431-443, 1999.

[3] Charalambides, M.N., Hardouin, R., Kinloch, A.J. Matthews, F.L., Adhesively-Bonded Repairs to Fibre-Composite Materials I: Experimental. Composites Part A: Applied Science and Manufacturing, 29(11), pp. 1371-81, 1998.

[4] Yi, S., Hilton, H. H., Ahmad M.F., A Finite Element Approach for Cure Simulation of Thermosetting Matrix Composites. Computers \& Structures, 64(1-4), pp. 383-388, 1997. 
[5] Stewart, I., Chambers, A., Gordon, T., The Cohesive Mechanical Properties of a Toughened Epoxy Adhesive as a Function of Cure Level. International Journal of Adhesion \& Adhesives, 27(4), pp. 277-287, 2007.

[6] Yu, H., Mhaisalkar, S.G., Wong, E.H., Teh, L.K. \& Wong, C.C., Investigation of Cure Kinetics and Its Effect on Adhesion Strength of Nonconductive Adhesives Used in Flip Chip Assembly. IEEE Transactions on Components and Packaging Technologies, 29(1), pp. 71-79, 2006.

[7] Loos, A.C., Springer, G.S., Curing of Epoxy Matrix Composites. Journal of Composite Materials, 17(2), pp. 135-169, 1983.

[8] Bogetti T.A., Gillespie, J.W., Two-Dimensional Cure Simulation of Thick Thermosetting Composites. Journal of Composite Materials, 25(3), pp. 239-273, 1991.

[9] Zhu, Q., Geubelle, P.H., Tucker, C.L., Dimensional Accuracy of Thermoset Composites: Simulation of Process-Induced Residual Stresses. Journal of Composite Materials, 35(24), pp. 2171-2205, 2001.

[10] Cheung, A., Yu, Y., Pochiraju, K., Three-Dimensional Finite Element Simulation of Curing of Polymer Composites. Finite Elements in Analysis and Design, 40(8), pp. 895-912, 2004.

[11] Patankar, S.V., Numerical Heat Transfer and Fluid Flow, Taylor \& Francis: Oxfordshire, 1980.

[12] Kamal, M.R., Sourour, S., Kinetics and Thermal Characterization of Thermoset Cure. Polymer Engineering \& Science, 13(1), pp. 59-64, 1973.

[13] Standard Test Method for Arrhenius Kinetic Constants for Thermally Unstable Materials Using Differential Scanning Calorimetry and the Flynn/Wall/Ozawa Method, ASTM E 698-05, 2005.

[14] Lee, C.L., Wei, K.H., Curing Kinetics and Viscosity Change of a Two-Part Epoxy Resin During Mold Filling in Resin-Transfer Molding Process. Journal of Applied Polymer Science, 77(10), pp. 2139-2148, 2000.

[15] Lee, J.Y., Choi, H.K., Shim, M.J., Kim, S.W., Kinetic Studies of an Epoxy Cure Reaction by Isothermal DSC Analysis. Thermochimica Acta, 343 (1-2), pp. 111-117, 2000.

[16] Mutnuri, B., Liang, R., GangaRao, H., Thermal Conductivity Characterization of FRP Composites: Experimental. ANTEC, May 7-11, Charlotte, NC, 2006. 